\title{
Evidence-based uncertainty: do implant-related properties of titanium reduce the susceptibility to perioperative infections in clinical fracture management? A systematic review
}

\author{
Michael C. Tanner ${ }^{1}\left[\right.$ (D) Christian Fischer $^{1} \cdot$ Gerhard Schmidmaier $^{1} \cdot$ Patrick Haubruck $^{1}$
}

Received: 28 September 2020 / Accepted: 2 February 2021 / Published online: 13 February 2021

(c) The Author(s), corrected publication 2021

\begin{abstract}
Background Implant-associated infections (IAI) remain a challenging complication in osteosynthesis. There is no consensus or clear evidence whether titanium offers a relevant clinical benefit over stainless steel.

Purpose In this systematic review, we sought to determine whether the implant properties of titanium reduce the susceptibility to IAI compared to stainless steel in fracture management.

Methods A systematic literature search in German and English was performed using specific search terms and limits. Studies published between 1995 and 1st June 2020 in the Cochrane library, MEDLINE and Web of Science databases were included. Only clinical studies comparing titanium and stainless steel implants regarding the susceptibility to infections were selected for detailed review.

Results Five studies out of 384 papers were identified and reviewed. From the studies meeting inclusion criteria one study was a systematic review, two studies were randomized controlled studies (RCT) and two studies were of retrospective comparative nature of level IV evidence.

Conclusion Our results show that currently, no proven advantage for titanium implants in respect to IAI can be seen in contemporary literature. Implants preserving periosteal blood-flow and minimising soft-tissue trauma show statistically significant benefits in reducing the incidence of IAI. Clinical studies providing reliable evidence regarding the influence of titanium implants on IAI and investigating the susceptibility of titanium to infection are necessary
\end{abstract}

Keywords Stainless steel implants · Titanium implants $\cdot$ Infection · Trauma surgery $\cdot$ Prevention of infection · Implant related infection

\section{Introduction}

Implant-associated infections are a feared complication in the context of osteosynthesis which can lead from impaired union to amputation of affected extremities [1]. In addition they have an immense socio-economic impact and may prolong the successful treatment of patients considerably. Despite improvements in implants, perioperative antibiotic prophylaxis and intraoperative management, IAI remain

Michael C. Tanner

michael.tanner@med.uni-heidelberg.de

1 HTRG-Heidelberg Trauma Research Group, Center for Orthopedics, Trauma Surgery and Spinal Cord Injury, Trauma and Reconstructive Surgery, Heidelberg University Hospital, 69118 Heidelberg, Germany a therapeutically challenge in trauma and reconstructive surgery.

Titanium's supposed better biocompatibility raised aspirations for advantages towards prevention of IAI. Uncoated implants made of surgical steel, titanium or its many alloys (Titanium 6\% Aluminum 7\% Niobium - TAN) are currently the most commonly used implant types in Trauma surgery [2]. One marked difference of these metals pertaining to IAI is their surfacing, which has a direct impact on their biocompatibility. Stainless steel is usually polished electrically, therefore showing a very smooth surface, whereas titanium is microporous. This pitted surface leads to osseous integration, whereas stainless steel is surrounded by soft tissue, leading to an avascular space between the two surfaces that are filled with fluid [3]. Initial in-vitro and invivo studies directly comparing the two different types of 
Table 1 Summary of the eligibility criteria

\begin{tabular}{|c|c|}
\hline Inclusion criteria & Exclusion criteria \\
\hline English language & Duplicate studies \\
\hline German language & $\begin{array}{l}\text { Studies investigating in only infectious behavior of titanium or stainless steel } \\
\text { implants }\end{array}$ \\
\hline Clinical studies & $\begin{array}{l}\text { Studies investigating in implants used for elective spinal and orthopaedic } \\
\text { surgery }\end{array}$ \\
\hline $\begin{array}{l}\text { Titanium versus stainless steel implants in fracture treatment } \\
\text { comparative studies }\end{array}$ & Studies investigating in implants used for endoprosthesis \\
\hline \multirow[t]{2}{*}{ Susceptibility of implant material to infections clearly discussed } & Pathological fractures \\
\hline & $\begin{array}{l}\text { Studies investigating in implants used for trauma management in facial } \\
\text { fractures }\end{array}$ \\
\hline
\end{tabular}

Table 2 Search strategy in the Cochrane library

\begin{tabular}{ll}
\hline Terms & Results \\
\hline MeSH descriptor: [Infection] explode all trees & 20,325 \\
MeSH descriptor: [Titanium] explode all trees & 748 \\
MeSH descriptor: [Stainless Steel] explode all trees & 265 \\
MeSH descriptor: [Postoperative Complications] explode & 33,257 \\
all trees & \\
MeSH descriptor: [Inflammation] explode all trees & 7505 \\
\#4 and \#2 and \#3 & 6 \\
(\#1 or \#5) and \#2 and \#3 & 2 \\
\#6 OR \#7*1995-current & 6 \\
\hline
\end{tabular}

implant materials showed a reduced susceptibility for titanium towards IAI in comparison with steel [2].

Almost three decades [4] after the introduction of titanium implants there is still no consensus or clear evidence whether titanium offers a relevant clinical benefit over stainless steel in the prevention of IAI. Hence, in this systematic review, we sought to determine whether the implant properties of titanium reduce the susceptibility to IAI compared to stainless steel in fracture management.

\section{Materials and methods}

A systematic literature search was performed according to PRISMA guidelines. In particular, the Cochrane library, MEDLINE, and Web of Science databases were searched on February 12th and 19th of 2019 and again 1st of June 2020. Strict eligibility criteria (Table 1) were applied based on the PICO criteria utilized for this review. Only studies published between 1995 and 1st of June 2020 were included in the review. The strategies for the performed searches are shown in Tables 2, 3 and 4. The identified studies were scrutinized using the Critical Appraisal Skills Program (CASP) checklist [5].
Table 3 Search strategy in the Medline database

\begin{tabular}{ll}
\hline Terms & Results \\
\hline 1 Stainless Steel/ & 6775 \\
2 "stainless steel".ti,ab,af & 16,166 \\
31 OR 2 & 16,166 \\
4 titanium.ti,ab,af & 48,065 \\
5 Titanium/ & 31,363 \\
64 OR 5 & 48,065 \\
73 AND 6 & 2325 \\
8 Infection/ & 35,800 \\
9 "infection".ti,ab,af & $1,085,492$ \\
10 infection/ OR postoperative complication/ OR bacte- & 529,409 \\
rial infection/ OR implant associated infection/ OR & \\
inflammation/ & \\
118 or 9 or 10 & $1,518,218$ \\
127 and 11 & 167 \\
13 limit 12 to yr= "1995 -Current" & 146 \\
\hline
\end{tabular}

\section{Eligibility criteria}

\section{Participants}

Patients suffering from a fracture of a bone of an extremity were included in the study regardless of age. Fractures of the vertebrae, skull, and mandibula, pathological fractures, and elective orthopaedic surgeries were excluded. A summary of the in- and exclusion criteria is demonstrated in Table 1.

\section{Intervention}

Surgical fracture fixation with titanium implants. 
Table 4 Search strategy in the Web of Science ${ }^{\circledR}$ database

\begin{tabular}{|c|c|}
\hline Terms & Results \\
\hline $1 \mathrm{TI}=$ "stainless steel*" & 20,320 \\
\hline \multicolumn{2}{|l|}{$\begin{array}{l}\text { Indexes = SCI-EXPANDED, SSCI Timespan = 1995- } \\
2017\end{array}$} \\
\hline $2 \mathrm{TS}=$ "stainless steel*" & 64,642 \\
\hline \multicolumn{2}{|l|}{$\begin{array}{l}\text { Indexes }=\text { SCI-EXPANDED, SSCI Timespan = 1995- } \\
2017\end{array}$} \\
\hline $\begin{array}{l}3 \# 1 \text { OR \#2 } \\
\text { Indexes = SCI-EXPANDED, SSCI Timespan = 1995- } \\
2017\end{array}$ & 64,642 \\
\hline $\begin{array}{l}4 \text { TI = "titanium*" } \\
\text { Indexes = SCI-EXPANDED, SSCI Timespan = 1995- } \\
2017\end{array}$ & 43,030 \\
\hline $\begin{array}{l}5 \text { TS = "titanium*" } \\
\text { Indexes = SCI-EXPANDED, SSCI Timespan = 1995- } \\
2017\end{array}$ & 150,133 \\
\hline $\begin{array}{l}6 \# 4 \text { or } \# 5 \\
\text { Indexes = SCI-EXPANDED, SSCI Timespan = 1995- } \\
2017\end{array}$ & 150,133 \\
\hline $\begin{array}{l}7 \text { \#3 and \#6 } \\
\text { Indexes = SCI-EXPANDED, SSCI Timespan =1995- } \\
2017\end{array}$ & 5864 \\
\hline $\begin{array}{l}8 \mathrm{TI}=(\text { infection* or "postoperative complication*" or } \\
\text { "bacterial infection*" or "implant associated infection*" } \\
\text { or inflammation*) }\end{array}$ & 331,482 \\
\hline $\begin{array}{l}\text { Indexes }=\text { SCI-EXPANDED, SSCI Timespan }=1995- \\
2017\end{array}$ & \\
\hline $\begin{array}{l}9 \mathrm{TS}=(\text { infection* or "postoperative complication*" or } \\
\text { "bacterial infection*" or "implant associated infection*" } \\
\text { or inflammation*) }\end{array}$ & $1,370,554$ \\
\hline $\begin{array}{l}\text { Indexes = SCI-EXPANDED, SSCI Timespan = 1995- } \\
2017\end{array}$ & \\
\hline $\begin{array}{l}10 \mathrm{TI}=\text { infection } * \\
\text { Indexes }=\text { SCI-EXPANDED, SSCI Timespan }=1995- \\
2017\end{array}$ & 260,052 \\
\hline $\begin{array}{l}11 \mathrm{TS}=\text { infection } * \\
\text { Indexes }=\text { SCI-EXPANDED, SSCI Timespan }=1995- \\
2017\end{array}$ & $1,016,147$ \\
\hline $\begin{array}{l}12 \# 8 \text { OR \#9 OR \#10 OR \#11 } \\
\text { Indexes = SCI-EXPANDED, SSCI Timespan=1995- } \\
2017\end{array}$ & $1,370,554$ \\
\hline $\begin{array}{l}13 \# 7 \text { and \#12 } \\
\text { Indexes = SCI-EXPANDED, SSCI Timespan = 1995- } \\
2017\end{array}$ & 232 \\
\hline
\end{tabular}

\section{Comparator}

Surgical fracture fixation with stainless steel implants.

\section{Outcomes}

1. Postoperative and perioperative infection of the implant and surgical site.

2. Susceptibility to perioperative infection associated with implant properties.

\section{Results}

A total of 384 studies were identified from the literature search (6 Cochrane library (Table 2), 146 MEDLINE (Table 3), 232 Web of Science (Table 4)). All duplicates were removed and all remaining titles and abstracts of the identified studies were checked for relevance by two independent reviewers (PH and MCT) according to the PRISMA guidelines. Finally, 10 studies were selected for full-text review following examination of their abstracts. Of these, 5 studies met the inclusion criteria. Additionally, all references of the articles selected for full-text review were checked for relevance according to the inclusion criteria (Fig. 1). All studies are summarized in Table 5.

From the studies that met the inclusion criteria one study was a systematic review, two studies were randomized controlled studies (RCT) and two studies were retrospective comparative studies of level IV evidence.

\section{Primary outcome}

Mohamed et al. published a systematic review 2016 [5]. Here they compared the clinical outcomes and complications of titanium versus stainless steel elastic nails in the management of paediatric femoral fractures. A total of five studies matched the inclusion criteria (a total of 198 titanium implants and 183 stainless steel implants were compared) and were evaluated regarding infections after treatment with steel and titanium elastic nails. None of the included studies showed a significant difference in the rate of infection between the two groups [5]. A total of two RCT were identified using the mentioned literature research in our study. Pieske et al. [6] published an RCT in 2008 investigating titanium alloy pins versus stainless steel pins in external fixation of the wrist. A total of 80 patients (320 pins) were treated with external fixation of the wrist, in particular, 40 patients were treated with stainless steel implants and 40 patients with titanium implants. The data of the study revealed no statistical differences among the two groups with regard to the prevalence of pin-site complications. However, the rate of premature removal of fixator because of severe pin-track infection (5\% vs. 0\%) was higher in the stainless steel group [6]. Another RCT was published 1996 by Arens et al. [7]. The authors investigated the rates of infection after open reduction and internal fixation with dynamic compression plates using both titanium and stainless steel implants. A total of 281 cases were evaluated (154 patients were treated with stainless steel implants and 127 with titanium implants). Regarding IAI the authors stated that no statistical difference was observed between the two groups. 


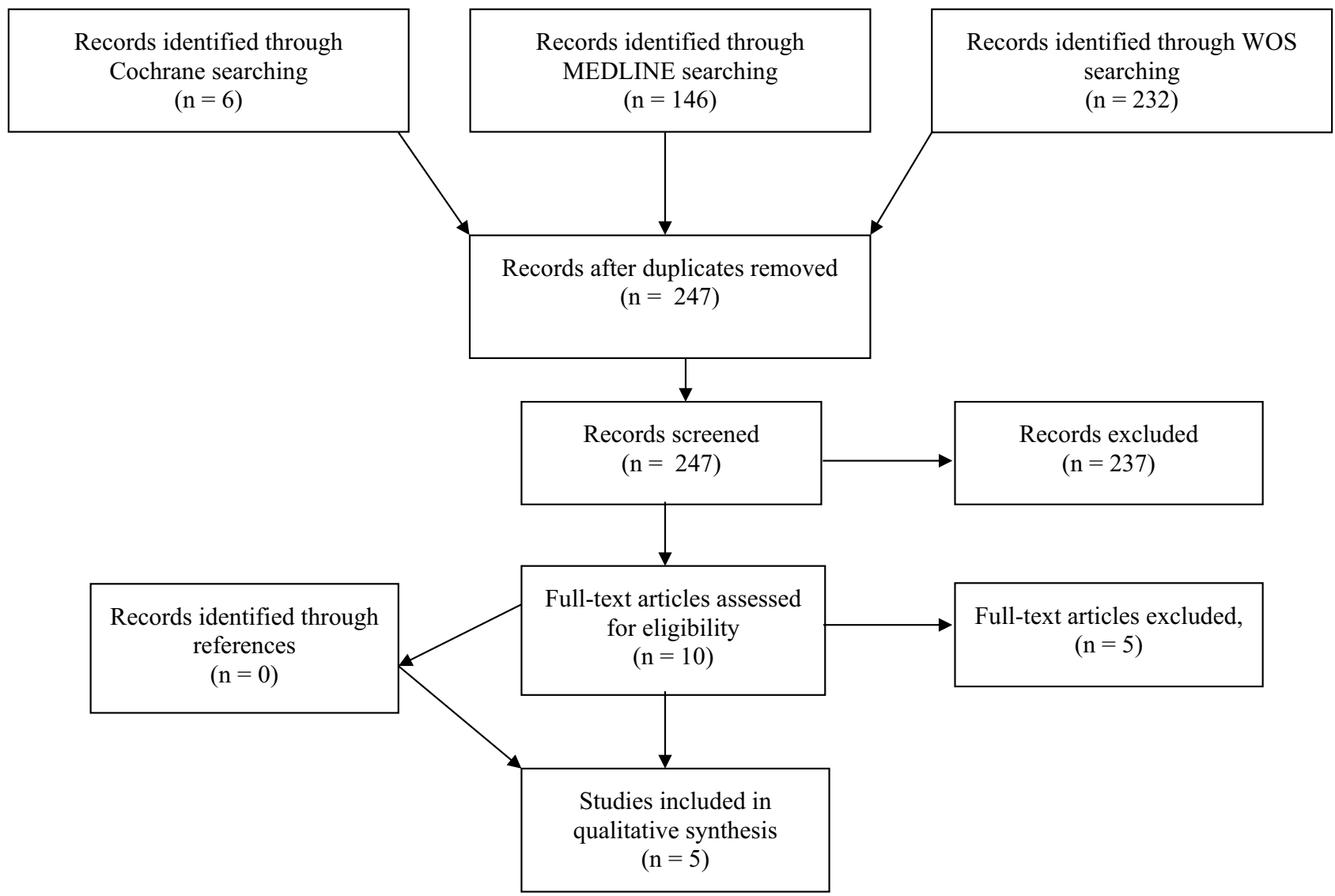

Fig. 1 Flowchart of the record identification and selection process. Based on the PRISMA guidelines

Table 5 Display of the summary of results

\begin{tabular}{|c|c|c|c|c|}
\hline Reference & $\begin{array}{l}\text { Year of } \\
\text { publica- } \\
\text { tion }\end{array}$ & Type of study & Title & $\begin{array}{l}\text { Influence on implant related } \\
\text { properties on the susceptibility to } \\
\text { infection }\end{array}$ \\
\hline \multicolumn{5}{|l|}{ Studies } \\
\hline Mohamed et al & {$[5]$} & Systematic review & $\begin{array}{l}\text { Clinical outcomes and complications of } \\
\text { titanium versus stainless steel elastic nail in } \\
\text { management of paediatric femoral fractures- } \\
\text { a systematic review }\end{array}$ & No statistical difference \\
\hline Pieske et al & [6] & $\mathrm{RCT}$ & $\begin{array}{l}\text { Titanium Alloy Pins Versus Stainless Steel Pins } \\
\text { in External Fixation at the Wrist: A Rand- } \\
\text { omized Prospective Study }\end{array}$ & No statistical difference \\
\hline Rozental et al & [8] & Retrospective clinical trial & $\begin{array}{l}\text { Functional Outcome and Complications Follow- } \\
\text { ing Two Types of Dorsal Plating for Unstable } \\
\text { Fractures of the Distal Part of the Radius }\end{array}$ & No statistical difference \\
\hline Voggenreiter et al & [9] & Retrospective clinical trial & $\begin{array}{l}\text { Immuno-inflammatory tissue reaction to } \\
\text { stainless-steel and titanium platesusedforinter- } \\
\text { nalfixationoflongbones }\end{array}$ & No statistical difference \\
\hline Arens et al & [7] & $\mathrm{RCT}$ & $\begin{array}{l}\text { Infection after open reduction and internal fixa- } \\
\text { tion with dynamic compression plates-Clini- } \\
\text { cal and experimental data }\end{array}$ & No statistical difference \\
\hline
\end{tabular}


A total of two retrospective trials were identified during our literature research. Rozental et al. [8] published the results of a retrospective trial in 2003. A total of 28 patients that were treated with dorsal plating for unstable fractures of the distal part of the radius were analyzed (14 patients were treated with titanium implants and 14 patients with stainless steel implants). No patients showed an early or late infection, regardless of implant material, during the study period averaging 21 months [8]. Voggenreiter et al. [9] published a retrospective trial in 2003 investigating the immuno-inflammatory tissue reaction to stainless-steel and titanium plates used for internal fixation of long bones. The immuno-inflammatory response to a total of 43 implants (21 stainless steel implants and 22 titanium implants) was analyzed. The results of this trial revealed a marked immuno-inflammatory reaction in the tissue surrounding the implants regardless of the implant material [9].

\section{Secondary outcome}

A total of three studies analyzed the influence of the implant properties on the susceptibility to IAI. Voggenreiter et al. stated that particles of both materials are phagocytosed by macrophages, which are activated and maintain chronic inflammation. No differences between the two materials with respect to this were detected [9]. The authors concluded that titanium was seemingly not as biologically inert as it was supposed to be several years before [9]. Pieske et al. mentioned that despite no statistical differences being detected, a higher incidence of severe pin-track infection occurred in the stainless steel group thereby supporting previous results indicating that titanium reduces the susceptibility to local infection [6]. Furthermore, Arens et al. [7] classified evaluated infection rates according to initial bacterial contamination after osteosynthesis with stainless steel and titanium implants and published the results in 1996. Regarding the susceptibility to IAI, their results showed that initial bacterial contamination and stainless steel implants tended towards a higher rate of IAI compared to titanium implants. However, the results were to a non-significant extent [7].

\section{Discussion}

Peri- and postoperative implant-associated infections (IAI) pose a severe complication of osteosynthesis in trauma surgery, which can lead to delayed- or non-union and even amputation of the affected extremity. IAI are potentially disastrous complications that have a high socio-economic impact as they profoundly delay patient's treatments. IAI may appear directly after surgery or in the extended postoperative course. Reasons for this are multifactorial and may be subdivided into the following risk-factors [10]:

1. Pathogenetic factors (i.e. fracture mechanism, location, initial contamination).

2. Patient individual factors (i.e. diabetes, immunosuppression, nicotine abuse, haematogenous contamination).

3. Iatrogenic factors (i.e. intraoperative contamination, unsterile instruments, perioperative contamination by the surgeon or other staff).

4. Implant associated factors (i.e. implant properties and condition, type of implant used).

It is common knowledge that closed fractures have a lower rate of infection than open ones (1,5\% vs, 3-40\%), especially considering that $60 \%$ of open fractures are initially contaminated by bacteria [11]. The incidence of IAI varies in the literature from $1 \%$ after surgical treatment of low-energy traumata up to $30 \%$ in complex open fractures $[11,12]$. The past decades have shown a continuous decline in IAI, for reasons yet unknown [13]. One reason might be a more consequent soft tissue management and perioperative antibiotic therapy.

IAI are in most cases due to contamination secondary either to initial trauma or intraoperative contamination, for example with skin flora. All known bacteria or fungi are principally capable of inducing IAI. The most common culprits are coagulase-negative staphylococci (30-43\%), staphylococcus aureus (12-23\%), streptococci (9-10\%), enterococci (3-7\%) or gram-negative bacilli $(3-6 \%)[14,15]$.

Strategies and guidelines have been implemented over the last years to reduce the risk for peri-operative infections and here the implant material represents only one factor amongst many. In orthopaedic surgery, hematogenous infection plays a minor role representing $0.3-7 \%$ of IAIs [16] while the main source of contamination remains the patient's skin and airborne particles from the theater personal [17]. Consequently, a study by Knobben et al. showed that behavioral changes of the theater personal and limiting not only the number of personal in the theater but also their movement led to a significant decrease of IAI [17]. Although it is commonly believed that the laminar airflow aids towards a reduction of IAI [17] evidence exists indicating that laminar airflow showed no benefit and was associated with an even higher risk for severe IAI after joint replacement [18] causing uncertainty. While these measures are intended to reduce the initial contamination of the surgical wound and implant itself, local and systemic antibiotic treatment are crucial to prevent the onset of IAI [19]. Here, novel strategies that have been given FDA approval include antibiotic coated intramedullary nails [20] and DAC coated intramedullary nails and plates $[21,22]$. 
The major challenge in IAI is the formation of biofilms, a biologically active matrix of cells and extracellular substances that associate with a metallic surface [10]. Biofilms are composed of bacteria adhering to a foreign body protected by an organic polymer. This protective substance is composed of extra-cellular polysaccharides that constitute an insoluble slimy secretion produced by bacteria. It protects bacteria from antibiotics, disinfectants, and defense mechanisms of the host [10]. The development of biofilms is divided into 5 steps, beginning with the attachment of a micro-colony on a foreign body, maturation, and development of a stable biofilm that comprehensively protects the bacteria, up to dispersion of individual microorganism and their dissemination in the bloodstream [10]. Infection with a bacterial biofilm can lead to local interruption of osteointegration and dissemination of pathogens may cause sepsis with impeding multi-organ failure and ultimately death of the affected patient. A relevant factor in biofilm development is the implant's composition. Numerous properties of implants have different effects on biocompatibility. It has been postulated that materials with increased biocompatibility might provide additional protection from biofilms [23]. However, it was shown that Staph aureus, Staph epidermidis and Pseudomonas aeruginosa are all capable of inducing biofilms on both steel and titanium implants [10].

Propionibacterium, recently reclassified as cutibacterium [24], are gram-positive, aerotolerant anaerobic bacteria of the normal skin microbiome [25]. While non-pathogenic colonization of cutibacterium can be found in the skin as well as the oral cavity and urogenital tract [26] recent studies identified Cutibacterium acnes as a causative pathogen of low-grade infection including generation of a biofilm only in the presence of an implant [27]. Diagnosis remains challenging as $\mathrm{C}$. acnes is often considered no more than a contaminant of the bacteriological cultures [28] and treatment requires long-lasting antibiotic regiments and often surgical revision [28]. While the majority of IAI in context with C. acnes has been reported in shoulder arthroplasty [29] cases of C. acnes on osteosynthetic implant material have been identified [28] requiring implant removal and an average of 5.7 months of adjuvant antibiotic treatment [28]. Evidence regarding the influence of the implant material on IAI caused by $\mathrm{C}$. acnes remains scarce. Interestingly, results from a recent animal study provided evidence that although C. acnes was able to generate biofilms on both titanium alloy and stainless steel a significantly denser biofilm was observed on titanium alloy [27]. The authors concluded that modification of the implant surface using nanotechnologies or coating strategies might prevent the onset of IAI caused by C. acnes [27].

Low-grade or late IAI are associated with less virulent bacteria such as C. acnes and S. epidermidis [30] and patients usually present with subtle or no clinical symptoms and elevated infectious laboratory parameters are missing. The most common sign of low-grade IAI is a compromised fracture healing and formation of a non-union [31]. Only a few studies have addressed the influence of implant material on low-grade IAI, here a recent study by Komnos et al. investigated the susceptibility of titanium alloy implants with different surface structures to low-grade IAI and found that modern osteointegrative surface topologies reduced the risk significantly [32]. While this strategy has important implications for joint replacing implants its transferability to osteosynthesis implant materials is limited as implant removal is common. Further studies are needed that investigate the influence of the implant properties on low-grade IAI.

Over $80 \%$ of microbial infections are due to biofilm generation [10]. Because of their numerous protective characteristics, biofilm contamination is extremely difficult to treat. Besides antibiotic treatment, most cases require surgical removal of the affected implant to successfully eradicate bacteria. This poses an additional risk for the patient. To protect them, it is sensible to use those implants which, due to their specific properties, help minimize the risk of biofilm formation. Currently, there are numerous types of implants with varying designs and properties for different anatomical regions and diverse osteosynthetic procedures. These properties and designs have a demonstrable effect on IAI.

Designs of current implants are continually being improved in terms of soft-tissue protection, periosteal preservation, and the guarantee of local microperfusion through the peri- and endosteum. Initial "dynamic compression plates" whose function was dependent on compression between plate and bone were soon superseded by the "limited contact dynamic compression plate" and "locking compression plate", which further reduced contact of the implant with the periosteum. Reduction of soft-tissue injuries, improved stability and protection of the microvascular environment were all shown to aid in the reduction of IAI, regardless of implant composition [33]. Intact periosteal soft-tissues have a positive influence on local cellular and humoral response, thereby increasing immunogenic response in combination with local vascularization [33].

Despite the immense clinical impact of IAI in trauma surgery, there are only a few relevant publications, most of which only regard this problem in vitro or in animal studies. Seligson et al. [34] performed an animal study on sheep in which they compared the in-vivo behavior of titanium and steel implants, especially their susceptibility for infections. Results of the study showed a slight reduction of IAI for titanium, albeit without statistical significance [34]. In a comparable animal model Ganser et al. showed in 2007 [35] that in external fixators, there was no significant difference in the use of Schanz screws made either of titanium or steel towards IAI [35]. Two further studies conducted on 
rabbit models by Johansson in 1999 [36, 37] comparing conventional steel plates (S-DCP) with monocortical titanium plates (PC-Fix) showed no statistical difference in terms of IAI. The authors noted that foreign material in general increases susceptibility for infection. The authors were further able to show that, independent of their material, S-DCPs are more susceptible to haemogenous IAI [36, 37]. Hudetz et al. (2008) [38] and Harris et al. (2007) [39] performed in vitro studies examining the effects of implant materials on Staphylococcus-infections. They reached the conclusion that the materials used are merely an inferior factor in susceptibility and infection rate with Staphylococcus aureus [38, 39]. They did, however, take note that the electropolished titanium surface was less vulnerable to Staphylococci invitro [39]. An animal study recently published by Metsemakers et al. in 2016 [40] came to the conclusion that titanium implants have no effect on the rate of infection. Weckbach et al. published a clinical retrospective cohort study in 2012 [41] which concluded that using steel implants for selected fractures does not increase the revision or complication rates. Even though this study makes no direct comparison of materials used, results showed no increased incidence of IAI in comparison to other published results [41]. Metsemakers et al. published a review in 2016 [2] in which implant materials had no effect on outcome of operative treatment of fractures. They did, however, speculate that the design of implants, especially plates, might show influence on IAI [2]. Implants sparing periosteal perfusion and avoiding softtissue injuries are believed to show benefits in regards to IAI. The same results were seen in a review by Schlegel et al. in 2006 [23]: the authors took up the study by Arens et al. [7] and were able to show that the design of implants, especially the protection of periosteal perfusion, had an advantageous influence on the development of IAI.

Evidence in clinical studies regarding the influence of implant properties on IAI and the susceptibility to infection remain scarce. During our literature research, we were able to identify merely five studies investigating this relevant complication. Furthermore, only three studies addressed the susceptibility to infections in association with the implant properties. However, the results of this systematic review support previous findings gathered in in-vitro and in-vivo studies. The results published by Voggenreiter et al. in 2001 [9] supported Johansson`s results from 1999 [36, 37] and showed in a clinical environment that implants lead to a softtissue reaction and inflammation regardless of the material used [9]. A further prospective study by Pieske et al. from 2008 [6] showed a slight reduction of pin track infections of external fixators when titanium pins were used to bridge distal radius fractures, albeit without statistical significance. Arens et al. came to a similar conclusion in 1996 [7] in their study combining animal experiments and a prospective randomized study. This also showed a slight tendency towards reduction of IAI for titanium, again without noted statistical significance [7]. Contrary to this the animal experiment showed significant differences for titanium and steel DCP`s susceptibility to IAI with advantages for titanium over steel. These results were not supported by the clinical part of the study [7]. The results of Rozental et al. [8] showed that no patients showed an early or late infection during the study period averaging 21 months regardless of the implant material used. In dorsal plating of the distal radius, complications arose due to differences in the design of implants [8]. A systematic review by Mohamed et al. from 2016 [5] compared the influence of implant materials in elastic nailing of children's femoral fractures on outcome and complications. The authors noted no difference in IAI dependent on implant materials [5].

\section{Conclusions}

IAI are a clinically relevant challenge in the treatment of trauma patients. Evidence of clinical studies regarding the influence of implant properties on IAI and the susceptibility to infection remain scarce. Many treatment algorithms were adapted from joint replacement surgery since evidencebased conclusions for trauma patients are meager, if not nonexistent [1]. The results of this review show that currently, no proven advantage for titanium implants in respect to IAI can be seen in contemporary literature. Solely slight tendencies towards a reduced susceptibility of titanium implants to IAI without statistical noteworthiness exist in the literature review. Despite this, implants that preserve periosteal blood-flow and reduce soft-tissue trauma have shown statistically significant benefits in reducing the incidence of IAI. Due to the results of the current review, we would like to strongly encourage further well-designed clinical studies to provide reliable evidence regarding the influence of titanium implants on IAI and investigate into the susceptibility of titanium to infection. Investigators planning studies in this field need to take the overall low incidence of IAI on osteosynthesis material into account when conducting a sample size calculation to ensure the adequate power of their studies.

Author contributions Study conception and design: PH, CF, GS, MCT. Acquisition of data: MCT, PH. Data extraction and critical evaluation: $\mathrm{PH}, \mathrm{MCT}$, GS. Analysis and interpretation of data: MCT, PH, CF, GS. Drafting of manuscript: MCT, PH, GS. Critical revision: GS, CF, PH, MCT. All authors read and approved the final version of this manuscript. Authorship eligibility guidelines according to the ICMJE were followed. The use of professional writers is not intended.

Funding Open Access funding enabled and organized by Projekt DEAL. We acknowledge financial support by Deutsche Forschungsgemeinschaft within the funding programme Open Access Publishing, by 
the Baden-Württemberg Ministry of Science, Research and the Arts and by Ruprecht-Karls-Universität Heidelberg.

\section{Compliance with ethical standards}

Conflicts of interest The authors declare that they have no competing interests.

Open Access This article is licensed under a Creative Commons Attribution 4.0 International License, which permits use, sharing, adaptation, distribution and reproduction in any medium or format, as long as you give appropriate credit to the original author(s) and the source, provide a link to the Creative Commons licence, and indicate if changes were made. The images or other third party material in this article are included in the article's Creative Commons licence, unless indicated otherwise in a credit line to the material. If material is not included in the article's Creative Commons licence and your intended use is not permitted by statutory regulation or exceeds the permitted use, you will need to obtain permission directly from the copyright holder. To view a copy of this licence, visit http://creativecommons.org/licenses/by/4.0/.

\section{References}

1. Metsemakers WJ, et al. Infection after fracture fixation: current surgical and microbiological concepts. Injury. 2016. https://doi.org/10. 1016/j.injury.2016.09.019.

2. Metsemakers WJ, et al. Influence of implant properties and local delivery systems on the outcome in operative fracture care. Injury. 2016;47:595-604.

3. Rochford ET, Richards RG, Moriarty TF. Influence of material on the development of device-associated infections. Clin Microbiol Infect. 2012;18:1162-7.

4. Matter P, Burch HB. Clinical experience with titanium implants, especially with the limited contact dynamic compression plate system. Arch Orthop Trauma Surg. 1990;109:311-3.

5. Mohamed A, Rajeev AS. Clinical outcomes and complications of titanium versus stainless steel elastic nail in management of paediatric femoral fractures-a systematic review. Eur J Orthop Surg Traumatol. 2016;27:157-67. https://doi.org/10.1007/s00590-016-1880-x.

6. Pieske $\mathrm{O}$, et al. Titanium alloy pins versus stainless steel pins in external fixation at the wrist: a randomized prospective study. $\mathrm{J}$ Trauma. 2008;64:1275-80.

7. Arens $\mathrm{S}$, et al. Infection after open reduction and internal fixation with dynamic compression plates-clinical and experimental data. Injury. 1996;27:SC27-33.

8. Rozental TD, Beredjiklian PK, Bozentka DJ. Functional outcome and complications following two types of dorsal plating for unstable fractures of the distal part of the radius. J Bone Joint Surg Am. 2003;85:1956-60.

9. Voggenreiter G, et al. Immuno-inflammatory tissue reaction to stainless-steel and titanium plates used for internal fixation of long bones. Biomaterials. 2003;24:247-54.

10. Veerachamy $\mathrm{S}$, et al. Bacterial adherence and biofilm formation on medical implants: a review. Proc Inst Mech Eng H. 2014;228:1083-99.

11. Harris LG, Richards RG. Staphylococci and implant surfaces: a review. Injury. 2006;37:S3-14.

12. Dapunt $\mathrm{U}$, et al. Evaluation of implant sonication as a diagnostic tool in implant-associated infections. J Appl Biomater Funct Mater. 2014;12:135-40.

13. Ktistakis I, Giannoudi M, Giannoudis PV. Infection rates after open tibial fractures: are they decreasing? Injury. 2014;45:1025-7.

14. Zimmerli W, Sendi P. Pathogenesis of implant-associated infection: the role of the host. Semin Immunopathol. 2011;33:295-306.
15. Zimmerli W, Moser C. Pathogenesis and treatment concepts of orthopaedic biofilm infections. FEMS Immunol Med Microbiol. 2012;65:158-68.

16. Ahnfelt L, et al. Prognosis of total hip replacement. A Swedish multicenter study of 4,664 revisions. Acta Orthop Scand Suppl. 1990;238:1-26.

17. Knobben BA, et al. Evaluation of measures to decrease intra-operative bacterial contamination in orthopaedic implant surgery. J Hosp Infect. 2006;62:174-80.

18. Brandt $\mathrm{C}$, et al. Operating room ventilation with laminar airflow shows no protective effect on the surgical site infection rate in orthopedic and abdominal surgery. Ann Surg. 2008;248:695-700.

19. Diefenbeck M, Muckley T, Hofmann GO. Prophylaxis and treatment of implant-related infections by local application of antibiotics. Injury. 2006;37:S95-104.

20. Moghaddam A, et al. Evaluation of the clinical use of the ETN PROtect(R) in non-union therapy. Injury. 2019;50:32-9.

21. Romano CL, et al. Antibacterial coating of implants: are we missing something? Bone Joint Res. 2019;8:199-206.

22. Malizos K, et al. Fast-resorbable antibiotic-loaded hydrogel coating to reduce post-surgical infection after internal osteosynthesis: a multicenter randomized controlled trial. J Orthop Traumatol. 2017;18:159-69.

23. Schlegel U, Perren SM. Surgical aspects of infection involving osteosynthesis implants: implant design and resistance to local infection. Injury. 2006;37:S67-73.

24. Scholz CFP. Kilian M The natural history of cutaneous propionibacteria, and reclassification of selected species within the genus Propionibacterium to the proposed novel genera Acidipropionibacterium gen. nov., Cutibacterium gen nov. and Pseudopropionibacterium gen. nov.,. Int J Syst Evol Microbiol. 2016;66:4422-32.

25. Renz N, et al. Orthopedic implant-associated infections caused by Cutibacterium spp. - A remaining diagnostic challenge. PLoS ONE. 2018;13:e0202639.

26. Achermann Y, et al. Propionibacterium acnes: from commensal to opportunistic biofilm-associated implant pathogen. Clin Microbiol Rev. 2014;27:419-40.

27. Shiono Y, et al. Delayed Propionibacterium acnes surgical site infections occur only in the presence of an implant. Sci Rep. 2016;6:32758.

28. Lutz MF, et al. Arthroplastic and osteosynthetic infections due to Propionibacterium acnes: a retrospective study of 52 cases, 19952002. Eur J Clin Microbiol Infect Dis. 2005;24:739-44.

29. Hsu JE, et al. Single-stage revision is effective for failed shoulder arthroplasty with positive cultures for Propionibacterium. J Bone Joint Surg Am. 2016;98:2047-51.

30. Steinmetz $\mathrm{S}$, et al. Infection after fracture fixation. EFORT Open Rev. 2019;4:468-75.

31. Tanner MC, et al. Non-union treatment based on the "diamond concept" is a clinically effective and safe treatment option in older adults. Clin Interv Aging. 2020;15:1221-30.

32. Komnos G, et al. Do trabecular metal and cancellous titanium implants reduce the risk of late haematogenous infection? An experimental study in rabbits. Hip Int. 2020. https://doi.org/10.1177/11207 00020928891.

33. Eijer H, et al. PC-Fix and local infection resistance-influence of implant design on postoperative infection development, clinical and experimental results. Injury. 2001;32:B38-43.

34. Seligson D, et al. In vivo study of stainless steel and Ti-13Nb$13 \mathrm{Zr}$ bone plates in a sheep model. Clin Orthop Relat Res. 1997;343:213-23.

35. Ganser A, et al. An in vivo experimental comparison of stainless steel and titanium Schanz screws for external fixation. Eur J Trauma Emerg Surg. 2007;33:59-68.

36. Johansson A, et al. Local plate infections in a rabbit model. Injury. 1999;30:587-90. 
37. Johansson A, et al. Material and design in haematogenous implantassociated infections in a rabbit model. Injury. 1999;30:651-7.

38. Hudetz D, et al. Weak effect of metal type and ica genes on staphylococcal infection of titanium and stainless steel implants. Clin Microbiol Infect. 2008;14:1135-45.

39. Harris LG, et al. Staphylococcus aureus adhesion to standard microrough and electropolished implant materials. J Mater Sci Mater Med. 2007;18:1151-6.
40. Metsemakers WJ, et al. Titanium and steel fracture fixation plates with different surface topographies: influence on infection rate in a rabbit fracture model. Injury. 2016;47:633-9.

41. Weckbach S, et al. Challenging the dogma on inferiority of stainless steel implants for fracture fixation. An end of the controversy? Unfallchirurg. 2012;115:75-9. 